\title{
Hypoxic Preconditioned Mesenchymal Stromal Cell Therapy in a Rat Model of Renal Ischemia-reperfusion Injury: Development of Optimal Protocol to Potentiate Therapeutic Efficacy
}

\author{
Myoung Jin Jang ${ }^{1,2}$, Dalsan You ${ }^{2}$, Jin Young Park ${ }^{3}$, Kyung Kim³ ${ }^{3}$ Joomin Aum², Chunwoo Lee ${ }^{4}$, \\ Geehyun Song, Ha Chul Shin ${ }^{6}$, Nayoung Suh ${ }^{7}$, Yong Man Kim ${ }^{6}$, Choung-Soo Kim ${ }^{2}$
}

${ }^{1}$ Asan Institute for Life Sciences, Asan Medical Center, University of Ulsan College of Medicine, Seoul, Korea, ${ }^{2}$ Department of Urology, Asan Medical Institute of Convergence Science and Technology, Asan Medical Center, University of Ulsan College of Medicine, Seoul, Korea, ${ }^{3}$ Department of Urology, Asan Medical Center, University of Ulsan College of Medicine, Seoul, Korea, ${ }^{4}$ Department of Urology, Gyeongsang National University Changwon Hospital, Gyeongsang National University School of Medicine, Changwon, Korea, ${ }^{5}$ Department of Urology, Kangwon National University Hospital, Chuncheon, Korea, ${ }^{6}$ Pharmicell Co. Ltd., Seongnam, Korea, ${ }^{7}$ Department of Pharmaceutical Engineering, College of Medical Sciences, Soon Chun Hyang University, Asan, Korea

Although previous and ongoing clinical studies have used stromal cells during renal ischemia-reperfusion injury (IRI), there is little consensus regarding the optimal protocol. We aimed to optimize the protocol for hypoxic preconditioned human bone marrow-derived mesenchymal stromal cell (HP-hBMSC) therapy in a rat model of renal IRI. We determined the optimal injection route (renal arterial, renal parenchymal, and tail venous injection), dose (low-dose: $1 \times 10^{6}$, moderate-dose: $2 \times 10^{6}$, and high-dose: $4 \times 10^{6}$ ), and injection period (pre-, concurrent-, and post-IRI). During optimal injection route study, renal arterial injections significantly reduced the decreasing glomerular filtration rate (GFR), as compared to GFRs for the IRI control group, 2 and 4 days after IRI. Therapeutic effects and histological recoveries were the greatest in the group receiving renal arterial injections. During the dose finding study, high-dose injections significantly reduced the decreasing GFR, as compared to GFRs for the IRI control group, 3 days after IRI. Therapeutic effects and histological recoveries were the greatest in the high-dose injection group. While determining the optimal injection timing study, concurrent-IRI injection reduced elevated serum creatinine levels, as compared to those of the IRI control group, 1 day after IRI. Pre-IRI injection significantly reduced the decreasing GFR, as compared with GFRs for the IRI control group, 1 day after IRI. Therapeutic effects and histological recoveries were the greatest in the concurrent-IRI group. In conclusion, the concurrent-IRI administration of a high dose of HP-hBMSC via the renal artery leads to an optimal recovery of renal function after renal IRI.

Keywords: Ischemia-reperfusion injury, Acute kidney injury, Hypoxia preconditioning, Cell therapy, Renal function

Received: August 25, 2018, Revised: August 28, 2018,

Accepted: October 12, 2018, Published online: November 30, 2018 Correspondence to Choung-Soo Kim

Department of Urology, Asan Medical Center, University of Ulsan College of Medicine, 88 Olympic-ro 43-gil, Songpa-gu, Seoul 05505, Korea

Tel: +82-2-3010-3734, Fax: +82-2-477-8928

E-mail: cskim@amc.seoul.kr

(a) This is an open-access article distributed under the terms of the Creative Commons Attribution Non-Commercial License (http://creativecommons.org/ licenses/by-nc/4.0/), which permits unrestricted non-commercial use, distribution, and reproduction in any medium, provided the original work is properly cited.

Copyright (C) 2018 by the Korean Society for Stem Cell Research

\section{Introduction}

Ischemia-reperfusion injury (IRI) is a common early event in a kidney transplant, following a partial nephrectomy. Acute tubular necrosis, impaired kidney function, and organ leukocyte infiltration are some of the major findings for this condition (1). The therapeutic application of stem cells enables the replacement of damaged cells with differentiated stem cells, and allows the use of paracrine mechanisms so that administered stem cells can 
exhibit organ-protective actions (2-5). Several studies have demonstrated the effective results of stem cell therapy for achieving recovery from acute kidney injury (AKI) (1, 6-10).

AKI is characterized by a deterioration in renal function over a period of hours to days, causing the kidney to fail to excrete nitrogenous waste products and maintain fluid and electrolyte homeostasis. AKI can result from decreased renal perfusion without cellular injury; an ischemic, toxic, or obstructive insult to the renal tubule; a tubulointerstitial process with inflammation and edema; or a primary reduction in the filtration capacity of the glomerulus (11). In hospitals, IRI is a common etiology of AKI $(11,12)$. AKI is considered an important independent risk factor for mortality (13). Decades of research have suggested that numerous chemical and biological agents cause beneficial effects in AKI models (14). Promising results have recently been obtained using cell-based therapies for the treatment of AKI and chronic kidney disease (CKD) $(15,16)$. We also found that a renal arterial infusion of adipose-tissue-derived stromal vascular fraction rescues renal function in a rat model of AKI induced by IRI (17). In a meta-analysis to assess the effects of mesenchymal stromal cell (MSC) therapy in rodent models with $\mathrm{AKI}$ or $\mathrm{CKD}$, it was found that MSC therapy tended to be more beneficial in rats with AKI induced by IRI (6). Mechanisms involving angiogenesis, stem cell homing, anti-inflammatory reactions, anti-oxidative stress, and immunomodulation have been established in previous studies (1, 7-10, 18-22). These cells home to the injury sites and function by secreting paracrine factors to limit injury in renal tubules and/or facilitate kidney repair, instead of differentiating into renal tubular cells (14). However, stem cells alone have limited therapeutic efficacies and studies using hypoxic preconditioned human bone marrow-derived mesenchymal stromal cell (HP-hBMSC), which increase stem cell efficacy, are underway $(23,24)$.

The microenvironment of MSCs in the bone marrow is thought to be immersed in low oxygen tension (hypoxia) (25). It is thus hypothesized that hypoxia can better preserve the biological behavior of MSC from bone marrow. In-vitro culture under hypoxic conditions has been shown to improve proliferation, multilineage differentiation, and colony-forming efficiency $(26,27)$. In addition, hypoxic preconditioned MSCs (HP-MSC) enhanced survival and promoted retention in vivo and Small MSCs primed with Hypoxia and Calcium ions (SHC-MSCs) exhibit enhanced stemness and immunomodulatory functions $(28,29)$. Therefore, we evaluated the preclinical efficacy of HP-hBMSCs in a rat model of AKI induced by IRI, to ensure that there was enough evidence for a clinical trial entry.

However, there is little consensus regarding the protocol for optimizing stem cell-based therapies, especially for renal IRI. In our present study, we aimed to develop a protocol for optimizing HP-hBMSC therapy in a rat model of renal IRI. Our analysis consisted of three parts, an optimal injection route study, a dose finding study, and an optimal injection timing study.

\section{Materials and Methods}

\section{Isolation and culture of HP-hBMSCs}

The study protocol was approved by the Institutional Review Board of Asan Medical Center, Seoul, Republic of Korea (2015-1123), and was in accordance with the declaration of Helsinki. After receiving their informed consent, bone marrow was obtained from healthy donors. All the manufacturing and product testing procedures for hBMSC generation were performed using good manufacturing practices (Pharmicell Co. Ltd., Seongnam, Gyeonggi, Republic of Korea). A previously described isolation protocol was used (30). Cells were cultured in Dulbecco's modified Eagle's medium-low glucose (Gibco, Grand Island, NY, US), containing $10 \%$ human plate lysate (PLUS $^{\mathrm{TM}}$ Cell Culture Supplement, Compass Biomedical, Inc. MA, US). Then, cells at passage 8 were cultured for $72 \mathrm{~h}$ in a hypoxia-conditioned incubator (at $37^{\circ} \mathrm{C}$ in $1 \%$ $\mathrm{O}_{2}, 5 \% \mathrm{CO}_{2}$ and $94 \% \mathrm{~N}_{2}$, for $72 \mathrm{~h}$ ). After hypoxic preconditioning, the HP-hBMSCs to be injected were harvested using trypsin, washed twice with $\mathrm{PBS}$ and once with Plasma Solution A inj. (Multiple Electrolytes Injection, Type 1, UPS; CJ Health Care) and resuspended to a final concentration of $1 \sim 4 \times 10^{6}$ cells in Plasma Solution A inj. Criteria for release of HP-hBMSCs for preclinical use included the absence of microbial contamination (bacteria, fungus, mycoplasma, or endotoxin), a viability greater than $70 \%$ after assessment using a trypan blue exclusion assay, the proven expression of CD73 and CD105 surface molecules, and absence of CD14, CD34, and CD45, via immune phenotyping by flow cytometric analysis.

\section{Animal care}

All aspects of animal care and treatment and the surgical procedures used conformed to the eighth edition of the Guide for the Care and Use of Laboratory Animals, published in 2011. The protocols for performing animal experiments were approved by the Institutional Animal Care and Use Committee of Asan Medical Center (2016-12- 
068). One-hundred-and-eighty 12-week-old male SpragueDawley rats were purchased from Orient Bio Inc. (Seongnam, Gyeonggi, Republic of Korea) and housed for 1 week for acclimatization. During the experiments, all rats were maintained under a $12 \mathrm{~h}: 12 \mathrm{~h}$ light/dark cycle (lights on at 08:00, lights off at 20:00), a temperature of $22 \pm 2^{\circ} \mathrm{C}$, and a humidity of $50 \sim 55 \%$, and ad libitum access to food and water was provided.

\section{Optimal injection route study}

Sixty 13-week-old rats were randomly and equally distributed into the following six groups (10 animals per group): sham, nephrectomy control, IRI control, renal arterial injection, renal parenchymal injection, and tail venous injection groups. Each rat was intramuscularly anesthetized with $0.3 \mathrm{ml}$ of tiletamine (Zoletil; Virbac Laboratories, Carros, France) and xylazine hydrochloride (Rompun, Bayer, Germany) in a 4:1 mixture. Laparotomy was performed in the sham group and right nephrectomy was performed in the nephrectomy control group, while right nephrectomy was performed and IRI of the left kidney was induced in the other four groups. IRI induction was performed in the left kidney as described previously (17). Rats from the renal arterial injection group were injected immediately prior to the induction of renal IRI with $1 \times 10^{6} \mathrm{HP}$-hBMSC/50 $\mu 1$ via a 33-gauge Hamilton syringe (Hamilton, Zurich, Swiss) that was inserted into the distal aorta after clamping the aorta above and below the left renal artery. The injection site was closed using TachoSil $^{\circledR}$ Sealant matrix (BBF Sterilisatoin Service $\mathrm{GmbH}$, Kernen, Germany), and the clamps were removed to restore aortic and renal blood flow. Rats from the renal parenchymal injection group were injected using a Hamilton syringe needle, which was pierced from the lower pole to the upper pole of the kidney. While pulling out the needle, the cells were gradually released from the syringe. Rats from the tail venous injection group were injected with $1 \times 10^{6} \mathrm{HP}-\mathrm{hBMSC} / 50 \mu \mathrm{l}$ through the tail vein using a 26-gauge Kovax-syringe (Koreavaccine, Gyeonggi, Republic of Korea). The renal function of all the rats was evaluated 4 days before and 1, 2, 3, 4, 7 and 14 days after IRI. They were sacrificed 14 days after IRI, and the kidney tissues were then collected for histological examination.

\section{Dose finding study}

Sixty 13 week-old rats were randomly and equally distributed into the following six groups (10 animals per group): sham, nephrectomy control, IRI control, low-dose $\left(1 \times 10^{6} \mathrm{HP}-\mathrm{hBMSC} / 100 \mu \mathrm{l}\right)$, moderate-dose $\left(2 \times 10^{6} \mathrm{HP}-\right.$ hBMSC/100 $\mu \mathrm{l})$ and high-dose $\left(4 \times 10^{6} \mathrm{HP}-\mathrm{hBMSC} / 100\right.$ $\mu$ l) groups. HP-hBMSC was injected through effective routes to protect the renal function during the optimal route study. IRI induction and the renal function evaluation method were similar to those for the optimal injection route study.

\section{Optimal injection timing study}

Sixty 13-week-old rats were randomly and equally distributed into the following six groups (10 animals per group): sham, nephrectomy control, and IRI control, pre-IRI ( 2 days before IRI), concurrent-IRI, and post-IRI (2 days after IRI) groups. An effective dose of HP-hBMSC was injected through the certain route to protect the renal function in studies to determine the optimal injection route and dose. The IRI induction process was similar to that followed in the above two studies, and all rats underwent kidney function evaluation 1 and 4 days before IRI, and $1,3,4,7$, and 14 days after IRI.

\section{Measurement of renal function and tissue preparation}

Serum levels of creatinine and blood urea nitrogen (BUN) and urine levels of creatinine were measured at these time points in all animals. Urine was collected from animals in a metabolic cage at $24 \mathrm{~h}$, to estimate the daily urine volume. The glomerular filtration rate (GFR) was calculated using the following equation for the creatinine clearance rate $(\mathrm{Ccr}): \mathrm{Ccr}(\mathrm{ml} / \mathrm{min} / 100 \mathrm{~g})=($ urine creatinine $\times 24 \mathrm{~h}$ urine volume $\times 100) /($ serum creatinine $\times$ $1440 \times$ body weight). Quantification of BUN and creatinine levels was performed using standard laboratory equipment at our hospital.

After rats were sacrificed, the kidney tissues of each rat were collected. Half of each kidney was cryopreserved in liquid nitrogen for protein extraction or immunofluorescence staining. The remaining half was fixed in $4 \%$ paraformaldehyde and embedded in paraffin prior to sectioning and immunohistochemistry analysis.

\section{Hematoxylin and Eosin staining and histopathological scoring of kidney tissue}

Four $\mu \mathrm{m}$ kidney specimen sections were prepared and stained with hematoxylin and eosin for light microscopic analysis. Histopathological scoring was carried out based on a previous study in a blind fashion (31). The tubular injury scores estimated by deriving the percentage of destroyed tubules in the outer medulla that showed a loss of brush border, tubular necrosis, tubular dilatation, and cast formation in 10 randomly chosen, non-overlapping fields $(200 \times)$ were as follows: 0 (normal histology), 1 ( $\leq$ 24\%), 2 (25 49\%), 3 (50 74\%) and 4 (75 100\%). Histo- 
pathological scoring was described in a previous study (18).

\section{Sirius red staining}

The slides were dipped in Xylene I and Xylene II, treated with Xylene III, and dipped in ethanol solutions in the following order: $100 \%$ to $90 \%$ and $80 \%$ to $70 \%$. After dipping slides in distilled water thrice, we dipped them in the Harris hematoxylin solution (Sigma, St. Louis cat no: HHS-16, MO, US). Sirius red reagent (Abcam, Cambridge, MA., US) was dropped on the slides and they were incubated. After dipping slides twice in the acid solution, we washed the slides thrice using distilled water, and then dipped them again in ethanol solutions $70 \%$ to $80 \%, 90 \%$, and $100 \%$ in 3 steps for each solution. We repeatedly dipped the slides in Xylene I and Xylene II, treated them with Xylene III, and covered the slides with coverslips using permanent mounting media.

\section{TUNEL Assay}

A TUNEL assay kit (Roche Molecular Biochemicals, Mannheim, Germany) was used. Each sectioned specimen was deparaffinized in xylene I, II, and III, and rehydrated in increasingly diluted ethanol solutions (diluted 100\%, followed by $90 \%$, and so on upto $70 \%$ ). After washing in distilled water, the slides were placed into a pretreatment solution (heat-induced epitope retrieval solution/ target retrieval solution). After washing, the protein blocking serum-free ready-to-use (Dako, Glostrup, Denmark) reagent containing $20 \%$ FBS was added into the sections, and they were incubated in a humid chamber. The tunnel reaction mixture was dispensed onto the slides, which were incubated in a $37^{\circ} \mathrm{C}$ humid chamber. Converter-PODs (Converter-Peroxidase) were dispensed and slides were incubated in a $37^{\circ} \mathrm{C}$ humid chamber. After washing, DABstarting working solution was added to the specimens and they were incubated.

\section{Immunohistochemistry}

Kidney sections (4 $\mu \mathrm{m}$ thick) were prepared for immunohistochemistry analysis from rats of each group. Tissue sections were placed on microslides and deparaffinized in xylene, hydrated in increasingly diluted serial ethanol solutions, and immersed in $3 \% \mathrm{H}_{2} \mathrm{O}_{2}$ to quench endogenous peroxidase activity. To permit antigen retrieval, all sections were microwaved for $15 \mathrm{~min}$ in Tris-EDTA buffer ( $\mathrm{pH}$ 9.0), prepared in distilled water. Next, the sections were incubated for $2 \mathrm{~h}$ at an ambient temperature with anti-Ki67 (1:200, Abcam, Cambridge, MA, US), anti-Glutathione reductase (GR; 1:2000,
Abcam), and anti-Glutathione peroxidase (GPx; 1:2000, Abcam) antibodies. After washing, the slides were incubated using a biotin-free polymeric horseradish peroxidase-linker antibody conjugate system (Dako, Glostrup, Denmark) for $30 \mathrm{~min}$ at an ambient temperature. The slides were washed, and chromogen development was performed for $10 \mathrm{~min}$. The slides were counterstained with Meyer's hematoxylin and mounted using Immu-mount (Fisher Scientific, Geel, Belgium). For image analysis, four randomly selected kidney fields per animal in both the cortex and the medulla (40 kidney fields per group) were photographed. Images were recorded at $40 \times$ magnification via a Panoramic viewer program software (3D Histech, Budapest, Hungary). All images were analyzed by using Adobe Photoshop CS2 to quantify signals. The results of proliferation are presented as the percentage of Ki67-positive areas to the total area in each field (cortex and medulla). A semiquantitative analysis was used to express GR and GPx as the percentage of the positive area in a blind fashion.

\section{Statistical Analysis}

All results are expressed as means \pm standard error values. Multiple groups were compared using 1-way analysis of variance followed by the Tukey's HSD (honest significant difference) test for post hoc comparison. All statistical tests were 2-sided, and statistical significance was defined as $\mathrm{p}<0.05, \mathrm{p}<0.01$, or $\mathrm{p}<0.001$. $\mathrm{p} \geq 0.05$ was not considered significant. The data were analyzed by using IBM SPSS Statistics Version 21 (IBM Corporation, Armonk, NY, US).

\section{Results}

\section{Viability and characterization of HP-hBMSCs}

The viability of HP-hBMSCs as assessed by trypan blue exclusion assay, was $89.30 \pm 7.41 \%$. Flow cytometric analysis showed that HP-hBMSCs were positive for MSC markers CD105 (99.41\%), CD73 (99.96\%), and HLA-ABC (99.65\%), and negative for hematopoietic markers CD45 (0.36\%), CD14 (1.42\%), CD80 (0.52\%), CD86 (0.47\%), CD40 (0.23\%), and HLA-DR (0.64\%) (Fig. 1A). The multilineage differentiation capacity was confirmed after observing the adipogenic and osteogenic differentiation (Fig. 1B).

\section{Optimal injection route study}

There were no significant differences in body weight and food intake among the groups (Supplementary Fig. S1A, S1B). The weight of the kidneys increased about 

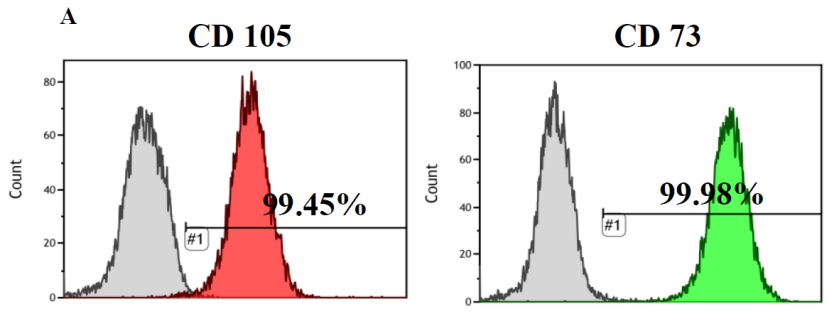

CD 45

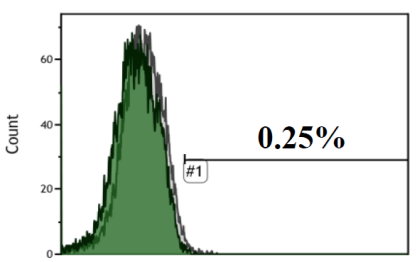

CD 14
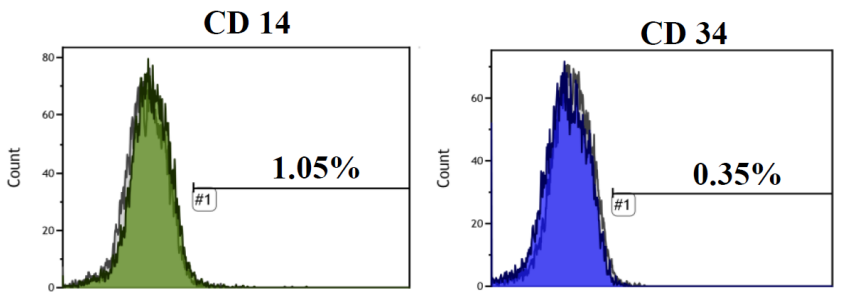

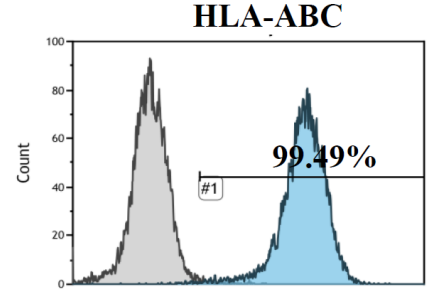

CD 80
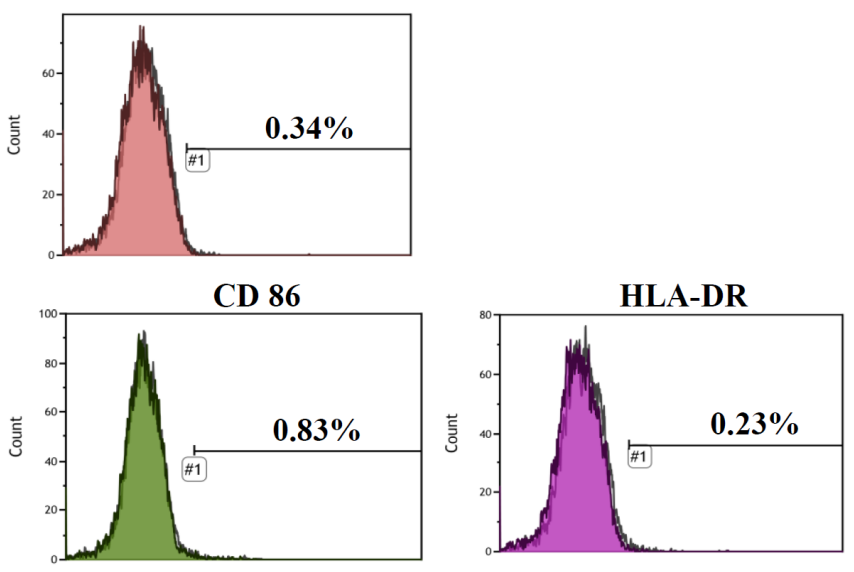

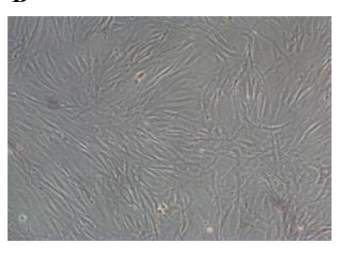

Morphology

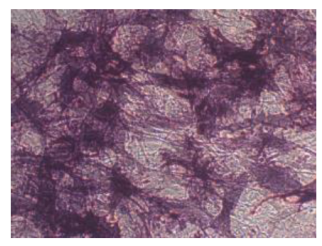

Osteogenesis

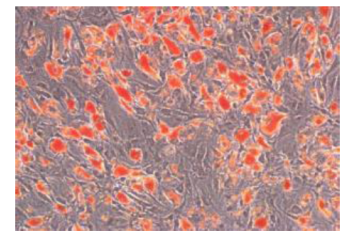

Adipogenesis

Fig. 1. Representative flow cytometric histograms and morphology of HP-hBMSCs. (A) FACS data of HP-hBMSCs. (B) Passage 8 morphology of HP-hBMSCs, and differentiation via adipogenesis and osteogenesis.

$0.6 \pm 0.3 \mathrm{~g}$, as compared to the sham group after nephrectomy, but no significant difference was observed between nephrectomy groups (Supplementary Fig. S1C). No gross differences in kidney cross-sections were observed (Supplementary Fig. S1D).

Two and 1 cases of mortality were observed in the renal parenchymal and tail venous injection groups, respectively. Renal arterial injection significantly reduced the extent of elevation in serum BUN values, as compared with those for the IRI control group, 1 and 14 days after IRI (Fig. 2A). Renal arterial injection significantly reduced the extent of elevation in serum creatinine, as compared with the IRI control group, 1, 7, and 14 days after IRI (Fig. 2B). Renal arterial injection significantly reduced the extent of decrease in the GFR, as compared with the GFR for the IRI control group, 2 and 4 days after IRI (Fig. 2C).
Histopathology scores were significantly different from those for the sham, nephrectomy control, and IRI control groups, but there was no significant difference in values for the IRI control and HP-hBMSC injection groups (Fig. 2D, 2E). Sirius red staining for collagen ratio was significantly increased in the IRI control group, as compared to that for the sham group. Sirius red staining in the cortex and medulla indicated that the renal arterial and parenchymal injection groups were significantly less fibrotic than the IRI control group (Fig. 2F, 2G). The TUNEL assay showed that apoptosis was more significantly decreased in the renal arterial injection group than in the IRI control group in both the cortex and medulla (Supplementary Fig. S2A, S2B). We used the Ki67 marker to determine proliferation; it was observed that the renal arterial injection group underwent increased proliferation in the cortex and medulla, as compared to the IRI control 

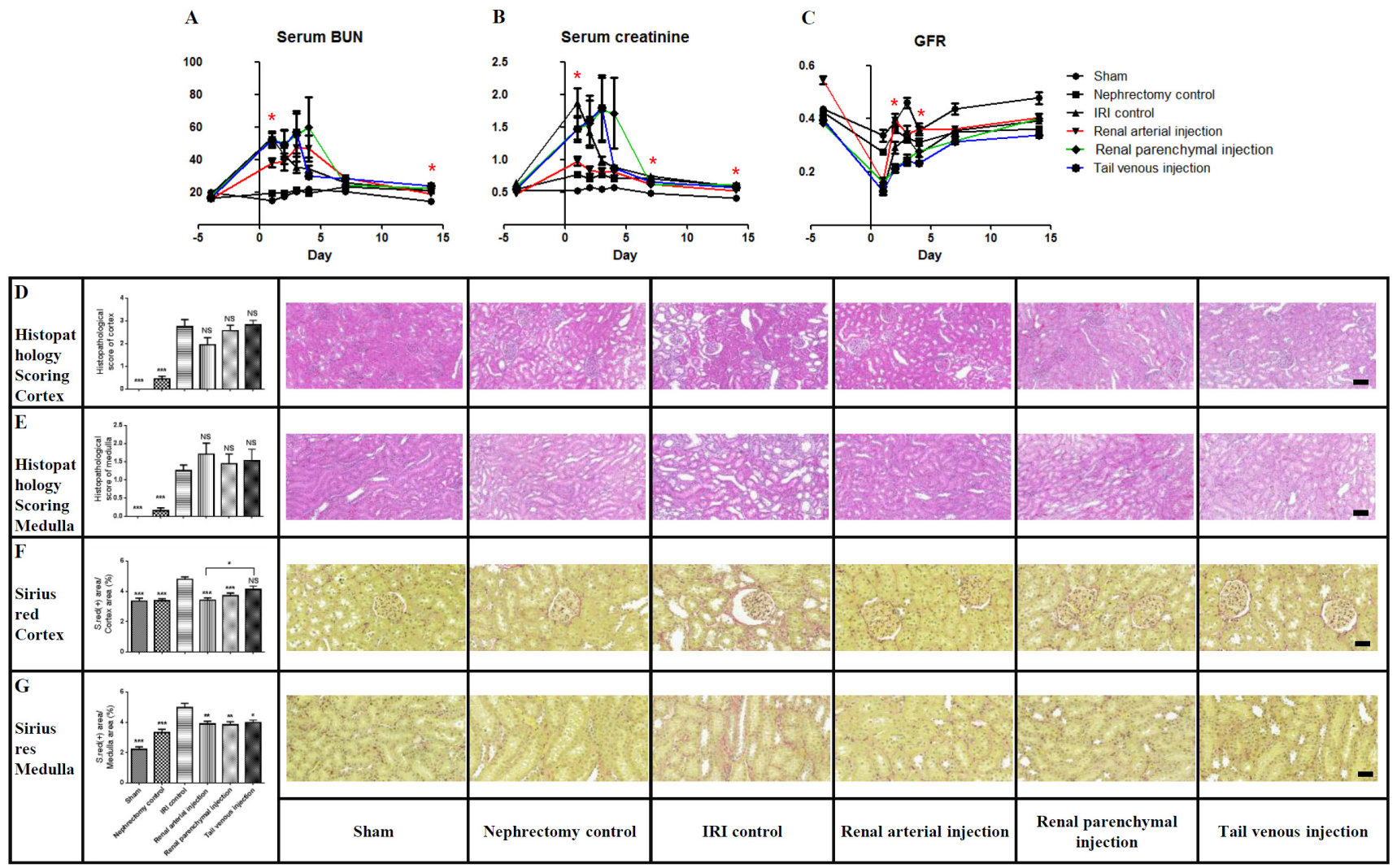

Fig. 2. Serum BUN, serum creatinine, GFRs, histopathological scoring, and Sirius red staining of kidney tissue in optimal injection route study. Serial changes in levels of (A) serum BUN, (B) serum creatinine, and (C) GFRs. (D) H\&E staining for histopathological score determination of each group in the kidney cortex and (E) medulla. Scale bar $50 \mu \mathrm{m}$. (F) Sirius red staining for determining degree of fibrosis for each group in the kidney cortex and (G) medulla. Scale bar $100 \mu \mathrm{m}$. NS, p $>0.05 ; *, p<0.05$; **, p $<0.01$; ***, and $\mathrm{p}<0.001$, as compared with the IRI control group.

group (Supplementary Fig. S2C, S2D). A greater increase in GR and GPx was observed in HP-hBMSC injection groups, especially for the arterial injection group in comparison with the IRI control group, regardless of the cortex or medulla regions (Supplementary Fig. S2F, S2G).

\section{Dose finding study}

There were no significant differences in body weight and food intake among groups (Supplementary Fig. S3A, S3B). The weight of the kidneys increased about $0.5 \pm 0.4$ $\mathrm{g}$ after nephrectomy, as compared to the sham group, but no significant difference was observed between nephrectomy groups (Supplementary Fig. S3C). No gross differences in kidney cross-sections were observed (Supplementary Fig. S3D).

One case of mortality was observed in the IRI control group. High-dose $\left(4 \times 10^{6}\right)$ injection significantly reduced the extent of elevation in the serum BUN level, as compared to that for the IRI control group, 1 and 2 days after IRI (Fig. 3A). High-dose injection significantly reduced the extent of elevation in serum creatinine, as compared to the IRI control group, 1 day after IRI (Fig. 3B). Highdose injection significantly reduced the extent of decrease in the GFR, as compared to the IRI control group, 3 days after IRI (Fig. 3C).

Histopathology scores were significantly different from those for the sham, nephrectomy control, and IRI control groups, but there was no significant difference between those for the IRI control and HP-hBMSC injection (Fig. 3D, 3E) groups. Results of Sirius red staining in the cortex and medulla indicated that all HP-hBMSC injection groups were significantly less fibrotic than the IRI control group (Fig. 3F, 3G). The TUNEL assay showed that apoptosis was more significantly decreased in all HP-hBMSC injection groups than in the IRI control group in both the cortex and medulla (Supplementary Fig. S4A, S4B). Ki67 showed that moderate-dose and high-dose injection groups underwent significantly increased proliferation, as compared to the IRI control group in both the cortex and medulla (Supplementary Fig. S4C, S4D). A greater increase 

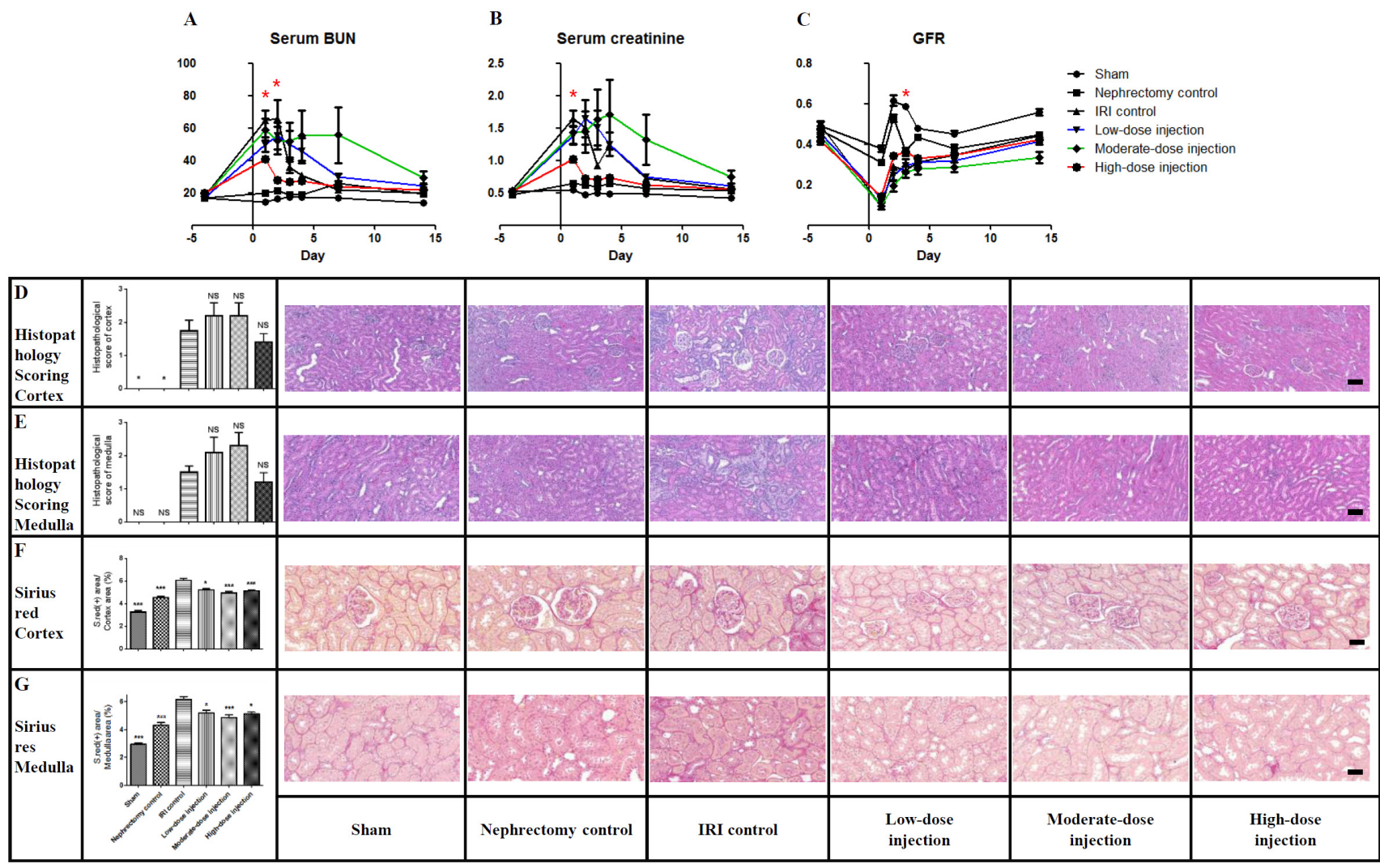

Fig. 3. Serum BUN, serum creatinine, GFRs, histopathological scoring, and Sirius red staining of kidney tissue in the dose finding study. Serial change in levels of serum BUN, (B) serum creatinine, and (C) GFRs. (D) H\&E staining for histopathological score determination in each group in the kidney cortex and (E) medulla. Scale bar: $50 \mu \mathrm{m}$. (F) Sirius red staining for determining the degree of fibrosis of each group in the kidney cortex and (G) medulla. Scale bar: $100 \mu \mathrm{m}$. NS, $\mathrm{p}>0.05 ;{ }^{*}, \mathrm{p}<0.05 ; * *, \mathrm{p}<0.01 ; * * *$, and $\mathrm{p}<0.001$, as compared with the IRI control group.

in GR and GPx was observed in moderate-dose and high-dose injection groups, as compared to the IRI control groups, regardless of whether the cortex or medulla was analyzed (Supplementary Fig. S4F, S4G).

\section{Optimal injection timing study}

There were no significant differences in body weight and food intake among groups (Supplementary Fig. S5A, S5B). The weight of the kidneys increased about $0.4 \pm 0.4$ $\mathrm{g}$ after nephrectomy, as compared to that of the sham group, but no significant difference was observed between nephrectomy groups (Supplementary Fig. S5C). No gross differences in kidney cross-sections were observed (Supplementary Fig. S5D).

One case of mortality was observed in the IRI control group. Pre-IRI injection significantly reduced the extent of elevation in serum BUN levels, as compared with those of the IRI control group, 1 day after IRI (Fig. 4A). Concurrent-IRI injection reduced the extent of elevation in serum creatinine levels, as compared with those of the
IRI control group, 1 day $(\mathrm{p}=0.054)$ after IRI (Fig. 4B). Pre-IRI injection significantly reduced the extent of decrease in GFRs, as compared with GFRs for the IRI control group, 1 day after IRI (Fig. 4C).

Histopathology scores were significantly different from those for the sham, nephrectomy control, and IRI control groups, but there was no significant difference in values for IRI control and HP-hBMSC injection groups (Fig. 4D and $4 \mathrm{E}$ ). Sirius red staining in the cortex and medulla indicated that all HP-hBMSC injection groups were significantly less fibrotic than the IRI control group (Fig. 4F and $4 \mathrm{G})$. The TUNEL assay showed that the apoptosis was more significantly decreased in all HP-hBMSC injection groups than in the medulla of the IRI control group (Supplementary Fig. S6A, S6B). Ki67 showed that all HP-hBMSC injection groups underwent significantly increased proliferation, as compared to the IRI control group in both the cortex and medulla (Supplementary Fig. S6C and S6D). A greater increase in GR and GPx levels was observed in all HP-hBMSC injection groups, as com- 

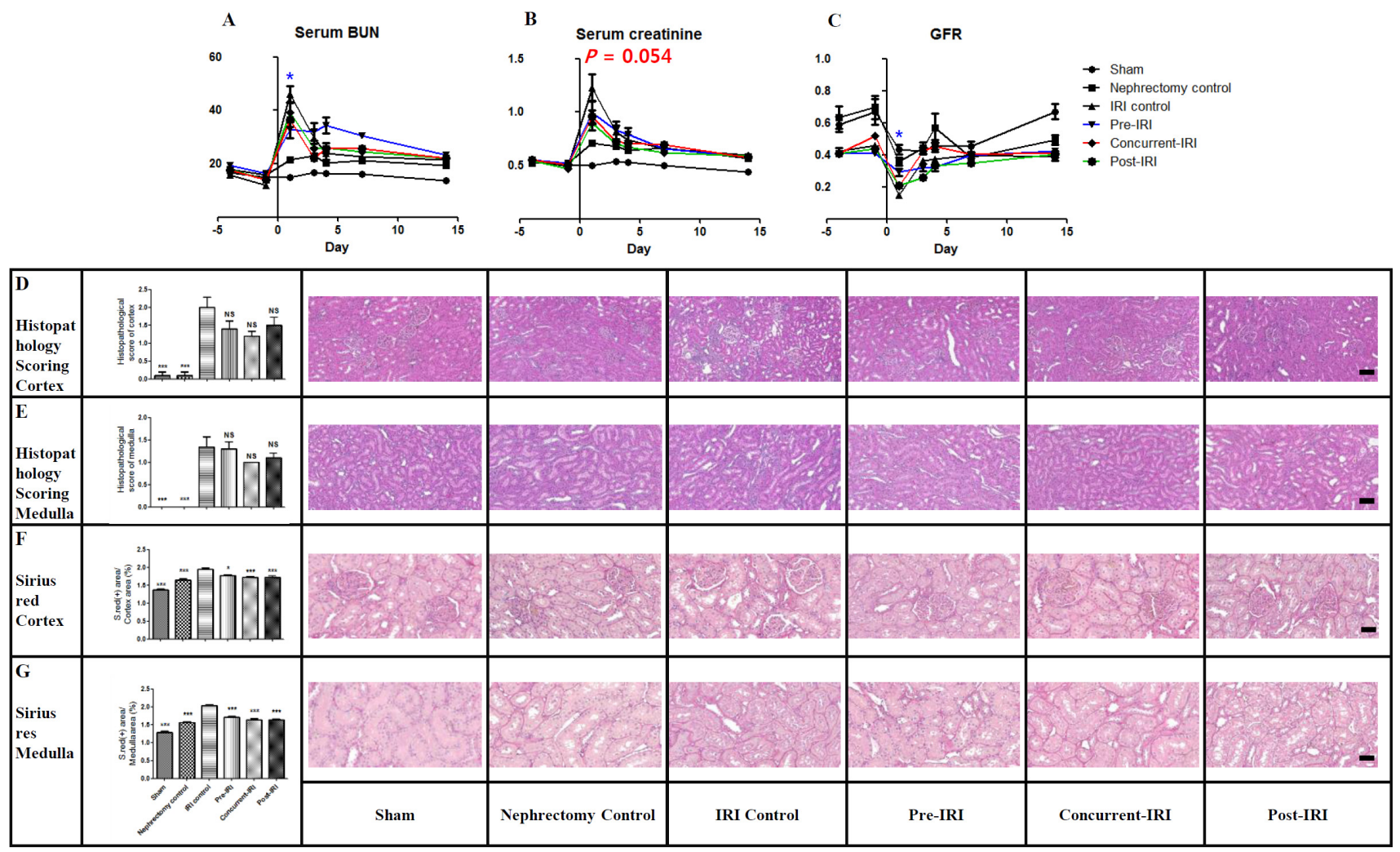

Fig. 4. Serum BUN, serum creatinine, GFRs, histopathology scoring, and Sirius red staining of kidney tissue in optimal injection timing study. Serial changes in levels of (A) serum BUN levels, (B) serum creatinine levels, and (C) GFRs. (D) H\&E staining for histopathological scoring of each group in the kidney cortex and (E) medulla. Scale bar: $50 \mu \mathrm{m}$. (F) Sirius red staining for determining the degree of fibrosis of each group in the kidney cortex and (G) medulla. Scale bar: $100 \mu \mathrm{m}$. NS, p $>0.05 ;{ }^{*}, \mathrm{p}<0.05 ; * *, \mathrm{p}<0.01 ;{ }^{* *}$, and $\mathrm{p}<0.001$. as compared with the IRI control group.

pared with those in the IRI control group, regardless of the analysis of the cortex or medulla (Supplementary Fig. S6F, S6G).

\section{Discussion}

Though several preclinical studies have confirmed the efficacy of stem cell-based therapies for AKI, there is little consensus regarding the optimal protocol for this treatment. Several issues from previous AKI studies remain unresolved. First, the optimal delivery route for cell-based therapies is unknown. Only a few studies had found that arterial delivery via the renal artery most effectively preserved renal function $(6,17,32)$. Second, the optimal stem cell dose is unknown. The number of cells transplanted in previous studies varied widely from $5 \times 10^{4}$ to $1 \times 10^{7}(32,33)$. The third and final unresolved issue pertains to the best time to inject cells. However, no study has addressed this question in a rat model of IRI to date. These unresolved issues motivated our current inves- tigation, in which we developed a protocol for optimizing HP-hBMSC therapy in a rat model of IRI.

We have investigated the therapeutic effects of HPhBMSC in AKI induced by IRI rescue in a rat model. First, an optimal injection route study was conducted, in which different routes of delivery were tested to establish the optimal route. The present study compared the renal arterial, renal parenchymal and tail venous routes for injecting HP-hBMSC. Our findings indicate that the renal arterial injection of HP-hBMSC effectively rescues renal function after AKI is induced by IRI. A meta-analysis of stem cell therapy in kidney diseases found that arterial delivery induced a greater reduction in serum creatinine levels than intravenous or intra-renal arterial injection (6). Our previous study demonstrated that renal arterial injection is more effective than renal parenchymal and tail venous injection for treating AKI (17).

Second, a dose finding study was conducted, in which different doses of HP-hBMSC were tested to establish the optimal dose. We found that a high-dose HP-hBMSC 
$\left(4 \times 10^{6} \mathrm{HP}-\mathrm{hBMSC}\right.$ per injection) treatment resulted in better outcomes; therefore, we subsequently used a high dose. However, Cai et al. (32) reported that maximal therapeutic efficiency was achieved with a renal arterial injection of $1 \times 10^{5}$ MSCs, which was significantly better than that for the group injected with $1 \times 10^{6}$ MSCs. Although it has been reported that the direct local arterial administration of stem cells increased the risk of tissue injury associated with occlusion and embolization, MSCs target oxidative stress and inflammation in both IRI phases, to protect the kidney (34), engraft in the injured tissue, and release soluble factors and microvesicles that promote cell survival and tissue repair (35). Unlike other studies, the effect of adding many cells was better, because cells were injected into the aorta instead of being directly injected into the renal artery. Hence, cells were injected into the syringe immediately prior to injection, to reduce the time for bundles of cells to get accumulated. Thus, it was anticipated that cells spread throughout the entire kidney might have played a role in reducing renal damage. Additionally, in other studies, the direct injection of cells into the renal artery could lead to vasospasms that narrow the vessel tract and make it vulnerable to embolisms, which could aggregate ischemia. The injection of stem cells into the renal artery though the aorta might be more effective than injection via other routes, because the homing of the cells was rapid, and cells were spread throughout the whole kidney.

Third, we aimed to determine the optimal cell injection period. Hence, we examined whether injecting cells at pre-IRI, concurrent-IRI, or post-IRI periods was more effective in protecting renal function. The results confirmed that the functioning and histology of the kidney was most effectively rescued from renal IRI through the pre- and concurrent-IRI injection of HP-hBMSC. There was a difference in the timing of injection of cells, but injecting cells within $24 \mathrm{~h}$, especially $1 \mathrm{~h}$ to $12 \mathrm{~h}$ after injury, was more effective. Lange et al. reported that transplanting MSCs either immediately or $24 \mathrm{~h}$ post-I/R resulted in significant renoprotection (21), and Liu et al. (36) reported that injecting cells immediately after ischemia or $1 \mathrm{~h}$ post-IRI yielded higher renoprotective and anti-inflammatory effects than when MSCs were administered 12 or $24 \mathrm{~h}$ post-IRI. IRI started an initiation stage, in which endothelial dysfunction progressed for several hours after injury, and progressed from the extension stage to the maintenance stage over time. Basile and Yoder (37) reported that treatment at the initiation stage resulted in the preservation of function, especially when treatments affecting tone (e.g., supplementation of NO or vasocon- strictor antagonists) were provided, while treatment at the extension stage lacked efficacy. Similarly, treatments that disrupt endothelial leukocyte interactions were effective when provided during initiation. Our current findings in the rat model suggest that that renal arterial injection of HP-hBMSC might be performed clinically when the kidney is exposed during surgery, while simultaneously assessing renal function impairment.

When the residual kidney is damaged by IRI during partial nephrectomy, HP-hBMSC could be injected into the renal artery during surgery for achieving renal function recovery; it would also be possible to perform this procedure for a transplanted kidney. Furthermore, the intra-renal arterial injection of HP-hBMSC could be performed through catheterization, by means of angiography or fluoroscopy for AKI, due to medical conditions. We believe that this would decrease the risk of chronic renal failure. In conclusion, administering a renal arterial, concurrent-IRI injection of high-dose HP-hBMSC can enable the recovery of renal function along with histomorphometric changes in a rat model of IRI.

\section{Acknowledgements}

This research was supported by a grant of the Korea Health Technology R\&D Project through the Korea Health Industry Development Institute (KHIDI), funded by the Ministry of Health \& Welfare, Republic of Korea (grant number: HI15C0925).

We thank the Comparative Pathology Core facility at the ConveRgence mEDIcine research cenTer (CREDIT), Asan Medical Center for measure the serum BUN, serum creatinine and urine creatinine.

\section{Potential Conflict of Interest}

There are no conflicts of interest to declare.

\section{Supplementary Materials}

Supplementary data including three figure can be found with this article online at http://pdf.medrang.co.kr/paper/ pdf/IJSC/IJSC-11-s18073.pdf.

\section{References}

1. da Silva LB, Palma PV, Cury PM, Bueno V. Evaluation of stem cell administration in a model of kidney ischemia-reperfusion injury. Int Immunopharmacol 2007;7:1609-1616

2. Gnecchi M, He H, Liang OD, Melo LG, Morello F, Mu H, Noiseux N, Zhang L, Pratt RE, Ingwall JS, Dzau VJ. Paracrine action accounts for marked protection of ische- 
mic heart by Akt-modified mesenchymal stem cells. Nat Med 2005;11:367-368

3. Kinnaird T, Stabile E, Burnett MS, Lee CW, Barr S, Fuchs S, Epstein SE. Marrow-derived stromal cells express genes encoding a broad spectrum of arteriogenic cytokines and promote in vitro and in vivo arteriogenesis through paracrine mechanisms. Circ Res 2004;94:678-685

4. Kinnaird T, Stabile E, Burnett MS, Shou M, Lee CW, Barr S, Fuchs S, Epstein SE. Local delivery of marrow-derived stromal cells augments collateral perfusion through paracrine mechanisms. Circulation 2004;109:1543-1549

5. Tögel F, Hu Z, Weiss K, Isaac J, Lange C, Westenfelder C. Administered mesenchymal stem cells protect against ischemic acute renal failure through differentiation- independent mechanisms. Am J Physiol Renal Physiol 2005; 289:F31-42

6. Wang Y, He J, Pei X, Zhao W. Systematic review and meta-analysis of mesenchymal stem/stromal cells therapy for impaired renal function in small animal models. Nephrology (Carlton) 2013;18:201-208

7. Li B, Cohen A, Hudson TE, Motlagh D, Amrani DL, Duffield JS. Mobilized human hematopoietic stem/progenitor cells promote kidney repair after ischemia/reperfusion injury. Circulation 2010;121:2211-2220

8. Tögel F, Weiss K, Yang Y, Hu Z, Zhang P, Westenfelder C. Vasculotropic, paracrine actions of infused mesenchymal stem cells are important to the recovery from acute kidney injury. Am J Physiol Renal Physiol 2007;292:F1626-F1635

9. Bi B, Schmitt R, Israilova $M$, Nishio H, Cantley LG. Stromal cells protect against acute tubular injury via an endocrine effect. J Am Soc Nephrol 2007;18:2486-2496

10. Dekel B, Shezen E, Even-Tov-Friedman S, Katchman H, Margalit R, Nagler A, Reisner Y. Transplantation of human hematopoietic stem cells into ischemic and growing kidneys suggests a role in vasculogenesis but not tubulogenesis. Stem Cells 2006;24:1185-1193

11. Thadhani R, Pascual M, Bonventre JV. Acute renal failure. N Engl J Med 1996;334:1448-1460

12. Schrier RW, Wang W, Poole B, Mitra A. Acute renal failure: definitions, diagnosis, pathogenesis, and therapy. J Clin Invest 2004;114:5-14

13. Kwon T, Jeong IG, Lee C, You D, Hong B, Hong JH, Ahn H, Kim CS. Acute kidney injury after radical cystectomy for bladder cancer is associated with chronic kidney disease and mortality. Ann Surg Oncol 2016;23:686-693

14. Yang Y, Song M, Liu Y, Liu H, Sun L, Peng Y, Liu F, Venkatachalam MA, Dong Z. Renoprotective approaches and strategies in acute kidney injury. Pharmacol Ther 2016;163:58-73

15. Chung HC, Ko IK, Atala A, Yoo JJ. Cell-based therapy for kidney disease. Korean J Urol 2015;56:412-421

16. Erpicum P, Detry O, Weekers L, Bonvoisin C, Lechanteur C, Briquet A, Beguin Y, Krzesinski JM, Jouret F. Mesenchymal stromal cell therapy in conditions of renal ischaemia/reperfusion. Nephrol Dial Transplant 2014;29: $1487-1493$
17. Lee C, Jang MJ, Kim BH, Park JY, You D, Jeong IG, Hong $\mathrm{JH}$, Kim CS. Recovery of renal function after administration of adipose-tissue-derived stromal vascular fraction in rat model of acute kidney injury induced by ischemia/reperfusion injury. Cell Tissue Res 2017;368:603-613

18. Chen YT, Sun CK, Lin YC, Chang LT, Chen YL, Tsai TH, Chung SY, Chua S, Kao YH, Yen CH, Shao PL, Chang KC, Leu S, Yip HK. Adipose-derived mesenchymal stem cell protects kidneys against ischemia-reperfusion injury through suppressing oxidative stress and inflammatory reaction. J Transl Med 2011;9:51

19. Yip HK, Chang LT, Wu CJ, Sheu JJ, Youssef AA, Pei SN, Lee FY, Sun CK. Autologous bone marrow-derived mononuclear cell therapy prevents the damage of viable myocardium and improves rat heart function following acute anterior myocardial infarction. Circ J 2008;72:1336-1345

20. Imberti B, Morigi M, Tomasoni S, Rota C, Corna D, Longaretti L, Rottoli D, Valsecchi F, Benigni A, Wang J, Abbate M, Zoja C, Remuzzi G. Insulin-like growth factor-1 sustains stem cell mediated renal repair. J Am Soc Nephrol 2007;18:2921-2928

21. Lange C, Tögel F, Ittrich H, Clayton F, Nolte-Ernsting C, Zander AR, Westenfelder C. Administered mesenchymal stem cells enhance recovery from ischemia/reperfusion-induced acute renal failure in rats. Kidney Int 2005;68:16131617

22. Behr L, Hekmati M, Fromont G, Borenstein N, Noel LH, Lelievre-Pegorier $M$, Laborde $K$. Intra renal arterial injection of autologous mesenchymal stem cells in an ovine model in the postischemic kidney. Nephron Physiol 2007;107:p65-76

23. Wei L, Fraser JL, Lu ZY, Hu X, Yu SP. Transplantation of hypoxia preconditioned bone marrow mesenchymal stem cells enhances angiogenesis and neurogenesis after cerebral ischemia in rats. Neurobiol Dis 2012;46:635-645

24. Singh A, Singh A, Sen D. Mesenchymal stem cells in cardiac regeneration: a detailed progress report of the last 6 years (2010-2015). Stem Cell Res Ther 2016;7:82

25. Spencer JA, Ferraro F, Roussakis E, Klein A, Wu J, Runnels JM, Zaher W, Mortensen LJ, Alt C, Turcotte R, Yusuf R, Côté D, Vinogradov SA, Scadden DT, Lin CP. Direct measurement of local oxygen concentration in the bone marrow of live animals. Nature 2014;508:269-273

26. Dos Santos F, Andrade PZ, Boura JS, Abecasis MM, da Silva CL, Cabral JM. Ex vivo expansion of human mesenchymal stem cells: a more effective cell proliferation kinetics and metabolism under hypoxia. J Cell Physiol 2010;223:27-35

27. Hoch AI, Leach JK. Concise review: optimizing expansion of bone marrow mesenchymal stem/stromal cells for clinical applications. Stem Cells Transl Med 2015;4:412

28. Beegle J, Lakatos K, Kalomoiris S, Stewart H, Isseroff RR, Nolta JA, Fierro FA. Hypoxic preconditioning of mesenchymal stromal cells induces metabolic changes, enhances survival, and promotes cell retention in vivo. Stem Cells 2015;33:1818-1828 
29. Kim Y, Jin HJ, Heo J, Ju H, Lee HY, Kim S, Lee S, Lim J, Jeong SY, Kwon J, Kim M, Choi SJ, Oh W, Yang YS, Hwang HH, Yu HY, Ryu CM, Jeon HB, Shin DM. Small hypoxia-primed mesenchymal stem cells attenuate graftversus-host disease. Leukemia 2018 May 22 [Epub]. doi: 10.1038/s41375-018-0151-8

30. You D, Jang MJ, Kim BH, Choi KR, Lee C, Song G, Shin HC, Jeong IG, Suh N, Kim YM, Ahn TY, Kim CS. Bone marrow-derived mesenchymal stromal cell therapy in a rat model of cavernous nerve injury: preclinical study for approval. Cytotherapy 2016;18:870-880

31. Melnikov VY, Faubel S, Siegmund B, Lucia MS, Ljubanovic D, Edelstein CL. Neutrophil-independent mechanisms of caspase-1- and IL-18-mediated ischemic acute tubular necrosis in mice. J Clin Invest 2002;110:10831091

32. Cai J, Yu X, Xu R, Fang Y, Qian X, Liu S, Teng J, Ding $\mathrm{X}$. Maximum efficacy of mesenchymal stem cells in rat model of renal ischemia-reperfusion injury: renal artery ad- ministration with optimal numbers. PLoS One 2014;9: e92347

33. Peired AJ, Sisti A, Romagnani P. Mesenchymal stem cell-based therapy for kidney disease: a review of clinical evidence. Stem Cells Int 2016;2016:4798639

34. Zhu XY, Lerman A, Lerman LO. Concise review: mesenchymal stem cell treatment for ischemic kidney disease. Stem Cells 2013;31:1731-1736

35. Bianchi F, Sala E, Donadei C, Capelli I, La Manna G. Potential advantages of acute kidney injury management by mesenchymal stem cells. World J Stem Cells 2014;6:644-650

36. Liu X, Cai J, Jiao X, Yu X, Ding X. Therapeutic potential of mesenchymal stem cells in acute kidney injury is affected by administration timing. Acta Biochim Biophys Sin (Shanghai) 2017;49:338-348

37. Basile DP, Yoder MC. Renal endothelial dysfunction in acute kidney ischemia reperfusion injury. Cardiovasc Hematol Disord Drug Targets 2014;14:3-14 
A

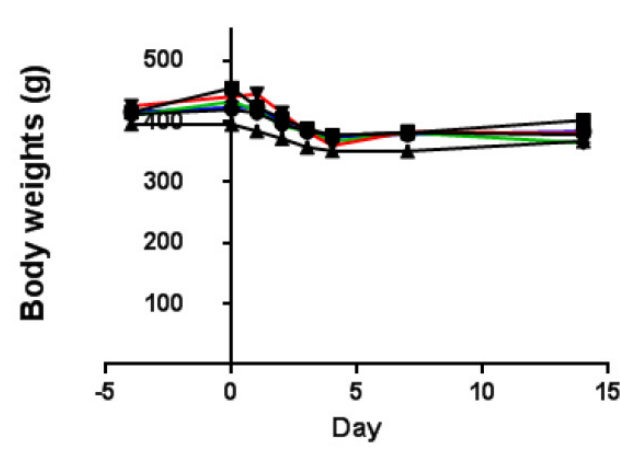

C

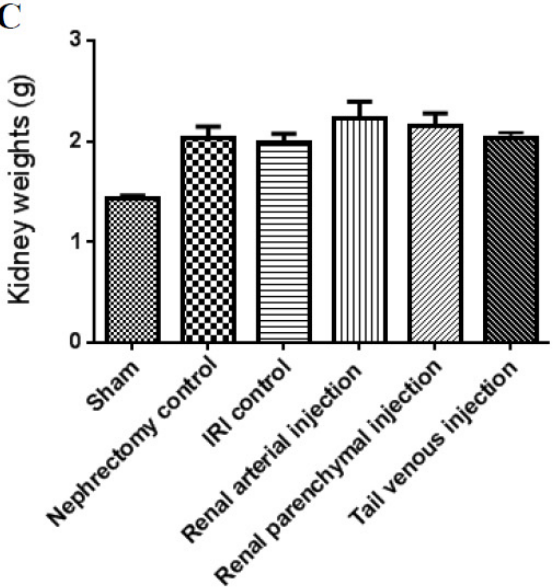

B

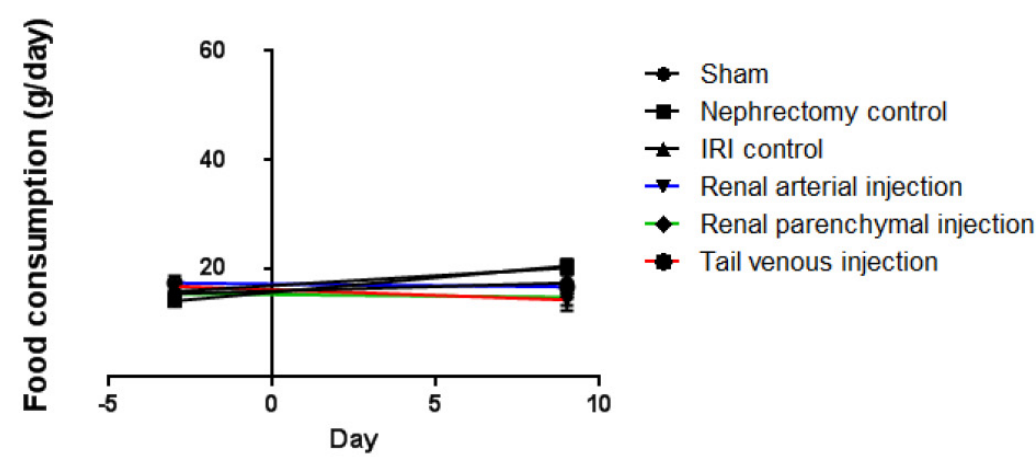

D

\begin{tabular}{|c|c|c|c|c|c|}
\hline Sham & $\begin{array}{c}\text { Nephrectom } \\
\text { y control }\end{array}$ & IRI control & $\begin{array}{c}\text { Renal } \\
\text { arterial } \\
\text { injection }\end{array}$ & $\begin{array}{c}\text { Renal } \\
\text { parenchyma } \\
\text { injection }\end{array}$ & $\begin{array}{c}\text { Tail venous } \\
\text { injection }\end{array}$ \\
\hline & & & & & \\
\hline
\end{tabular}

Fig. S1. Body weights and food consumption of rats, and kidney weights and morphology in optimal injection route study. Changes in the (A) Body weight, (B) Food consumption, and (C) Kidney weights of each group during the experiment. (D) Kidney morphology of each group. 


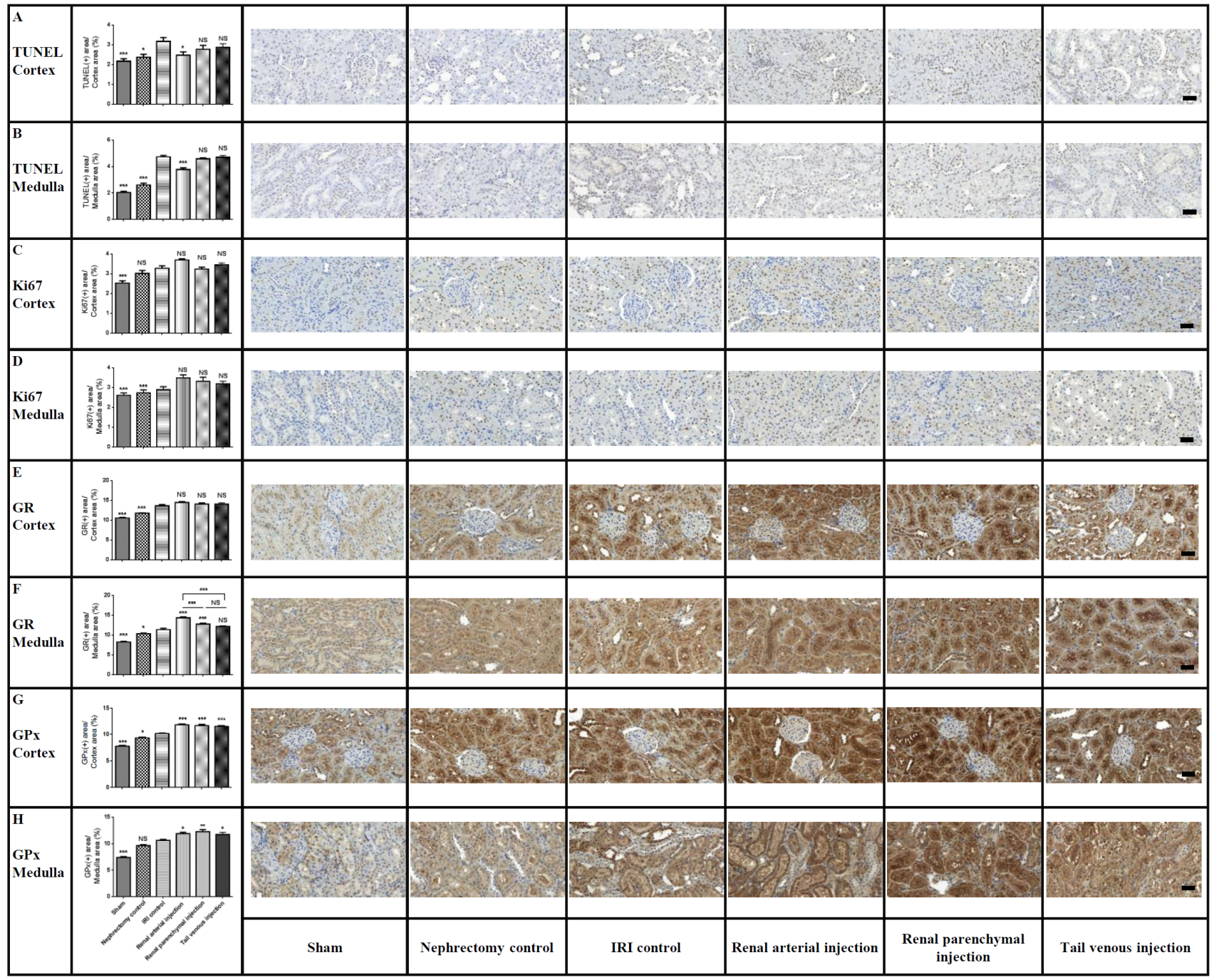

Fig. S2. Immunohistochemistry of TUNEL, Ki67, GR and GPx in optimal injection route study. (A) TUNEL assay for the detection of apoptotic cells of each group in the kidney cortex and (B) medulla. (C) Ki67 staining for detecting cell proliferation of each group in the kidney cortex and (D) medulla. (E) Glutathione reductase staining for oxidative cell detection in each group of the kidney cortex and (F) medulla. (G) Glutathione peroxidase staining for oxidative detection of each group in the kidney cortex and $(\mathrm{H})$ medulla. Scale bar $100 \mu \mathrm{m}$. NS, $\mathrm{p}>0.05 ; *, \mathrm{p}<0.05 ; * *, \mathrm{p}<0.01 ; * *$, and $\mathrm{p}<0.001$, as compared with the IRI control group. 

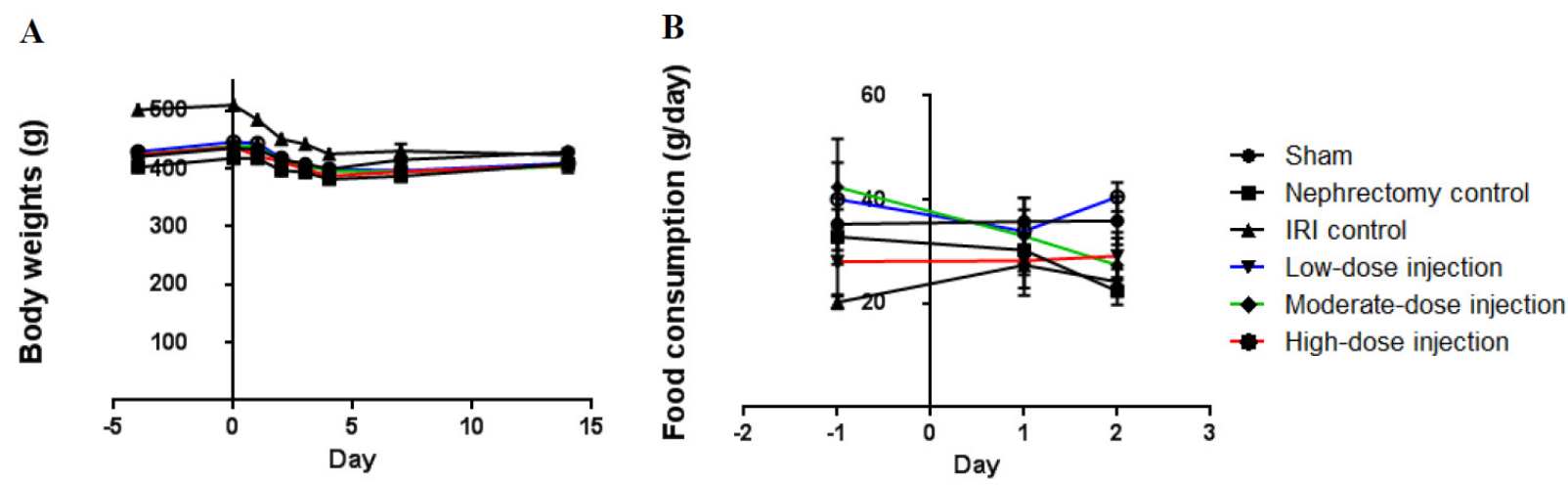

C

D

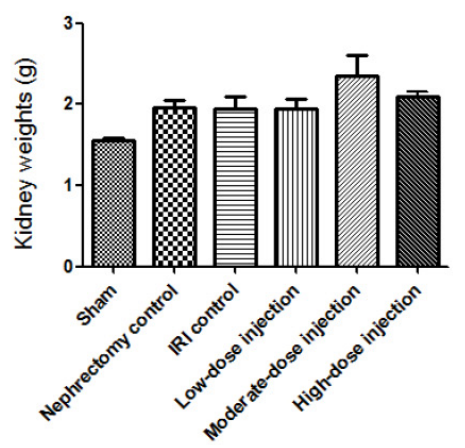

\begin{tabular}{|c|c|c|c|c|c|}
\hline Sham & $\begin{array}{c}\text { Nephrectom } \\
\text { y control }\end{array}$ & IRI control & $\begin{array}{c}\text { Low-dose } \\
\text { injection }\end{array}$ & $\begin{array}{c}\text { Moderate- } \\
\text { dose } \\
\text { injection }\end{array}$ & $\begin{array}{c}\text { High-dose } \\
\text { injection }\end{array}$ \\
\hline & & & & & \\
\hline
\end{tabular}

Fig. S3. Body weights and food consumption in rats, and kidney weights and morphology in the dose finding study. Graphs showing changes in (A) Body weight, (B) Food consumption, and (C) Kidney weight of each group during the experiment. (D) Kidney morphology of each group. 


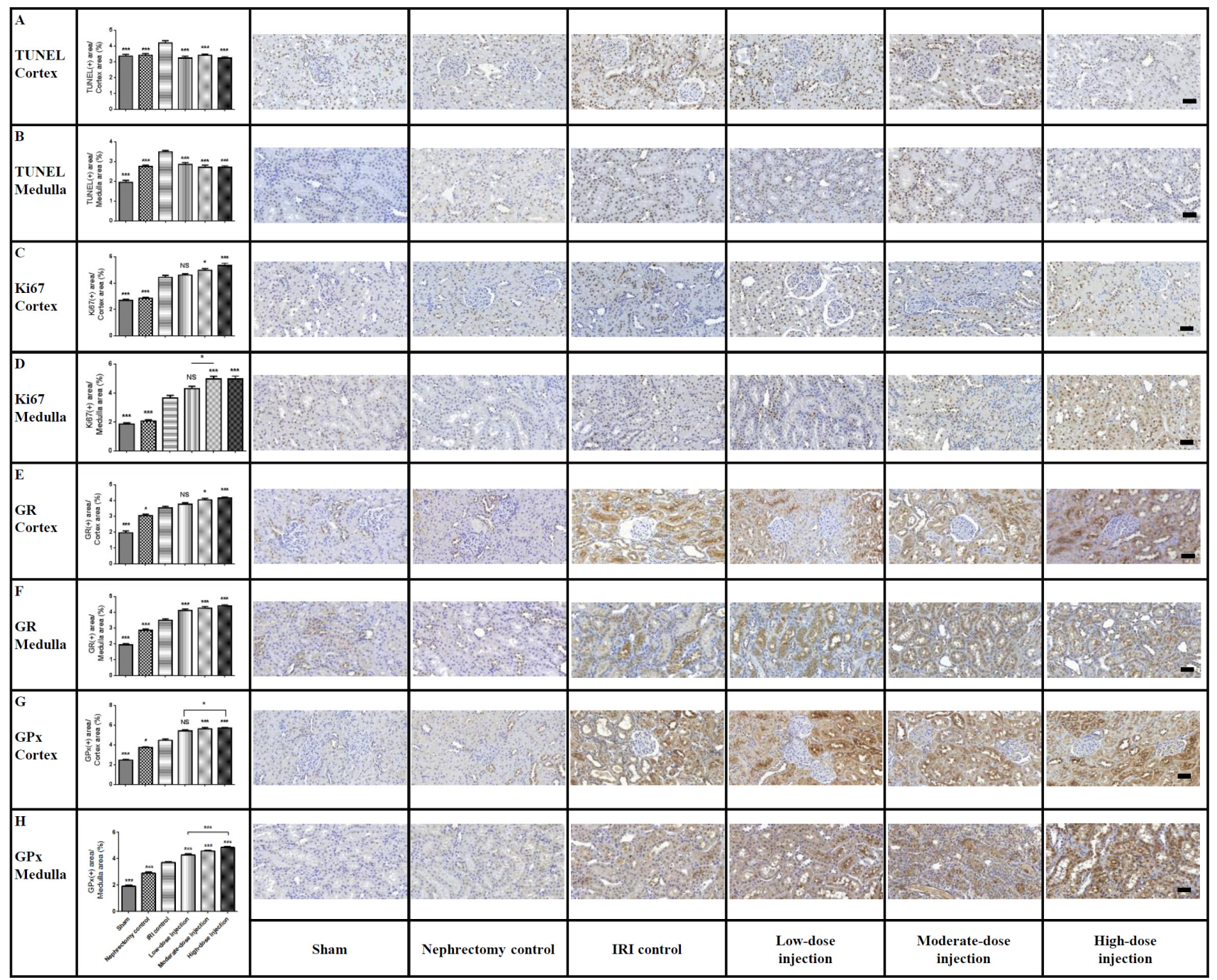

Fig. S4. Immunohistochemistry of TUNEL, Ki67, GR and GPx in dose finding study. (A) TUNEL assay for detecting apoptotic cells in each group of the kidney cortex and (B) medulla. (C) Ki67 staining for detecting cell proliferation in each group in the kidney cortex and (D) medulla. (E) Glutathione reductase staining for detecting oxidative cells in each group in the kidney cortex and (F) medulla. (G) Glutathione peroxidase staining for the oxidative detection of each group in the kidney cortex and $(\mathrm{H})$ medulla. Scale bar: $100 \mu \mathrm{m}$. NS, $\mathrm{p}>0.05$; $*, \mathrm{p}<0.05 ; * *, \mathrm{p}<0.01 ; * * *$, and $\mathrm{p}<0.001$, as compared with the IRI control group. 
A

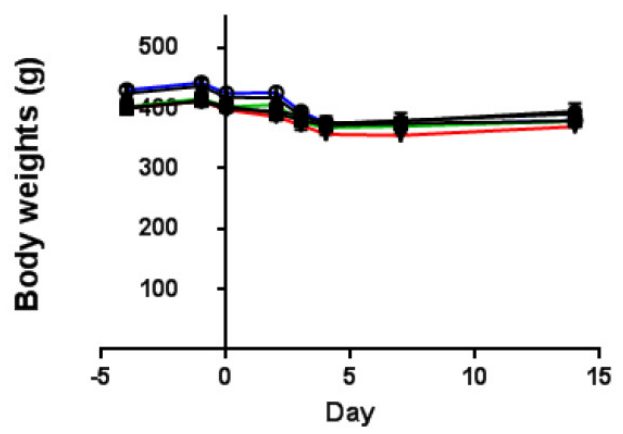

C

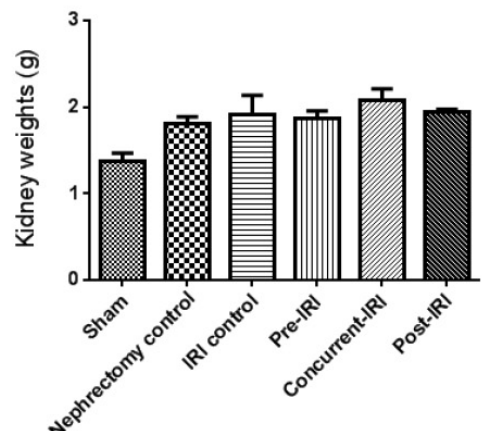

B

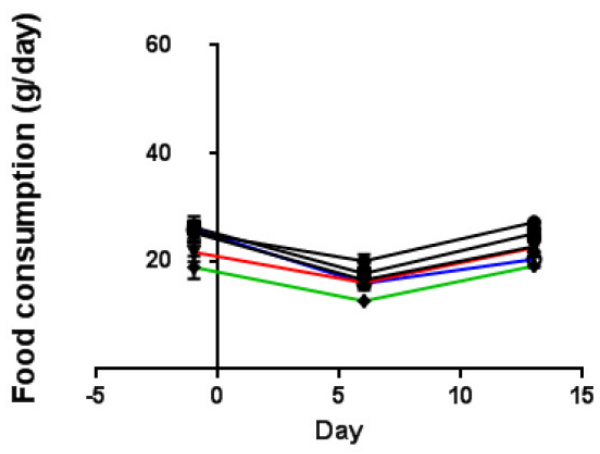

$\rightarrow$ Sham

- Nephrectomy control

^IRI control

$\rightarrow$ Pre $\dashv R$

- Concurrent-IRI

๑ Post-IRI

Fig. S5. Body weights and food consumption of rats, and kidney weights and morphology in the optimal injection timing study. Graphs showing the changes in (A) Body weight, (B) Food consumption, and (C) Kidney weight in each group during the experiment. (D) Kidney morphology of each group.

D

\begin{tabular}{|c|c|c|c|c|c|}
\hline Sham & $\begin{array}{c}\text { Nephrectom } \\
\text { y control }\end{array}$ & IRI control & Pre-IRI & $\begin{array}{c}\text { Concurrent- } \\
\text { IRI }\end{array}$ & Post-IRI \\
\hline & 4 & & & & \\
\hline
\end{tabular}




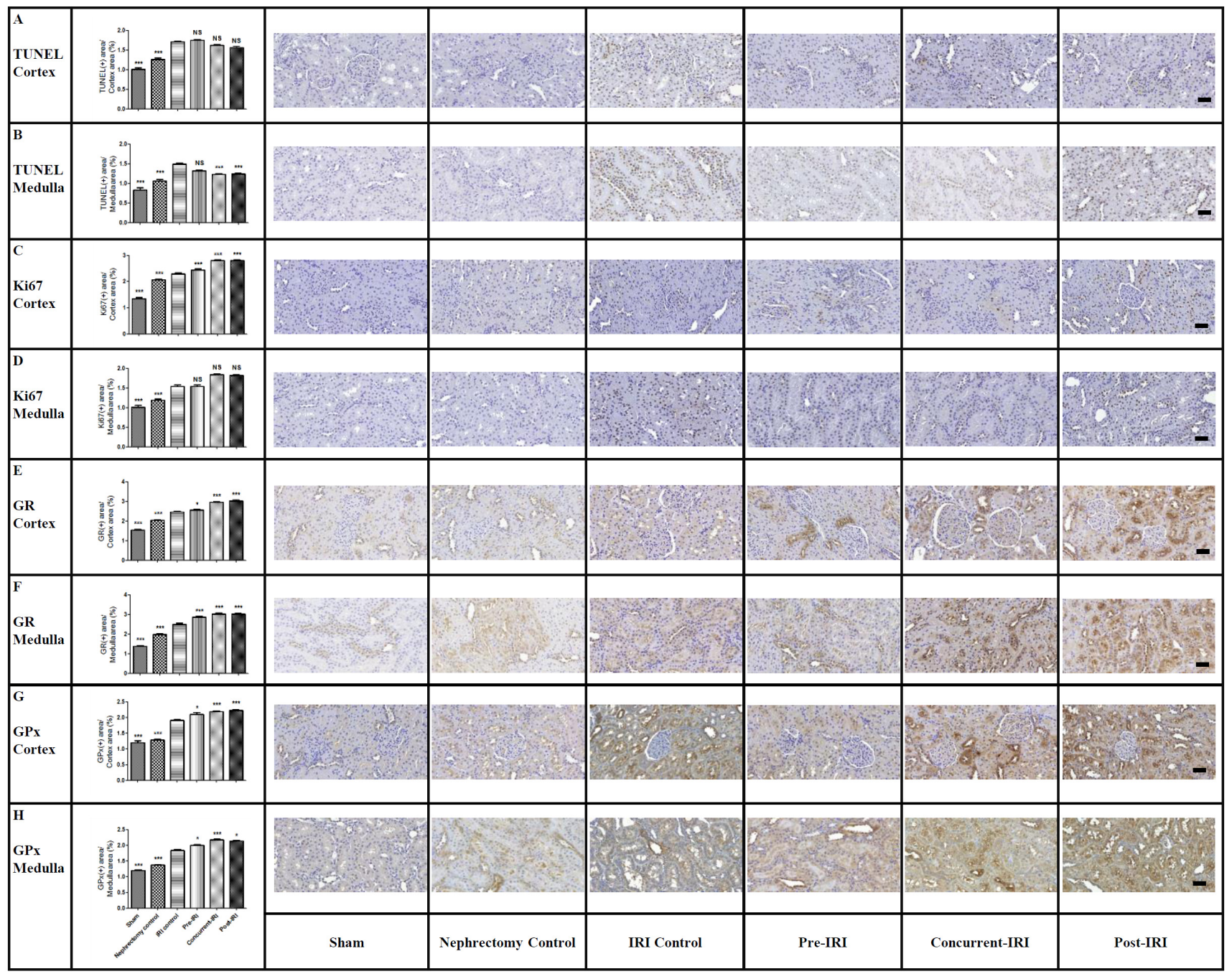

Fig. S6. Immunohistochemistry of TUNEL, Ki67, GR, and GPx in optimal injection timing study. (A) TUNEL assay for the detection of apoptotic cells of each group in the kidney cortex and (B) medulla. (C) Ki67 staining for detecting cell proliferation in each group of the kidney cortex and (D) medulla. (E) Glutathione reductase staining for oxidative cell detection in each group in the kidney cortex and (F) medulla. (G) Glutathione peroxidase staining for oxidative detection of each group in the kidney cortex and $(\mathrm{H})$ medulla. Scale bar: $100 \mu \mathrm{m}$. NS, $\mathrm{p}>0.05 ; *, \mathrm{p}<0.05 ; * *, \mathrm{p}<0.01 ; * * *, \mathrm{p}<0.001$, as compared with the IRI control group. 